\title{
Automatic Tuning for FOREX Trading System Using Fuzzy Time Series
}

\author{
Kraimon Maneesilp and Pitikhate Sooraksa
}

\begin{abstract}
Efficiency of the automatic currency trading system is time dependent due to using fixed parameters which are most effective in specific period of time. This paper presents a method of optimizing automatic currency trading system by adjusting its time variant parameters using fuzzy time-series forecasting to predict the trend of parameters. Improved prediction for two sets of time series forecasting with fuzzy relations is also illustrated.
\end{abstract}

Index Terms - Fuzzy time-series, forecast, foreign exchange, FOREX.

\section{INTRODUCTION}

Investment in currency markets have progressed significantly. The current investment products are developed to be the automatic trading systems which are becoming more popular. Research on the financial forecasts often predicts merely on how much the prices would increase or decrease [1], [2]. This information is not sufficient to be employed for automatic trading system. Because it does not even want to know that the price will increase or decrease but acquires to know the time for open-position and closed position [3], which typically uses a technical indicator to decide various open and closed position by setting some parameter values for decision making [4]. However, the efficiency of automatic trading system is sensitive to some known-characteristics of the market.

This paper presents an algorithm to determine parameters of an automated trading system to ensure more efficient in all aspects of the market. The proposed algorithm uses fuzzy time series to change parameters rather than predict direct exchange rate trend. The results were compared to the results of the system when the parameters are constant at most profitable during the experiment. The test will be carried out using the period from May 3, 2010 to July 6, 2010. The exchange rate of the EURO-US\$ by the profits and losses will be based on total number of Pips during the experiment.

Since we have two time-series in consideration, in this paper, we proposed a fuzzy time series methods modified from Chen's method [5] using the vector to assist the forecasted output process.

Manuscript received April 9, 2012; revised May 24, 2012.

Kraimon Maneesilp is with the School of Computer Engineering Faculty of Engineering, King Mongkut's Institute of Technology Ladkrabang, Ladkrabang, Bangkok, Thailand (kraimon@hotmail.com).

Pitikhate Sooraksa is with the School of Computer Engineering and Information Science, Faculty of Engineering, King Mongkut's Institute of Technology Ladkrabang, Ladkrabang, Bangkok, Thailand.

\section{TEMPlate MOdEl of AN AUtOMATIC TRAdING SySTEM}

To make the test clear and simple, the automatic trading system is adopted from the experimental work using Relative Strength Index (RSI) [6] as the indicator in the decision to open the order to buy / sell in the market. This is because RSI is very simple to understand and is one of the high probability trending patterns in FOREX market [7]. However, the system is protected from the open order to prevent the opening by the fault signals. This system has two parameters. They are RSI Up and RSI Down. The RSI Up is the value that determines when RSI is higher than the setting values. In this case, the system will open order "sell". In contrary, the RSI Down is the value that determines when the RSI is lower than the setting value; this will open the order "buy". Every order configuration takes profit at 10 Pips and is configured Stop loss at 100 Pips. In a certain period of time the system considers order at most one order and waits until the old order is clear out by Take Profit or Stop Loss before it opens new order. The operation procedure of the system is presented as the flow chart in Fig. 1.

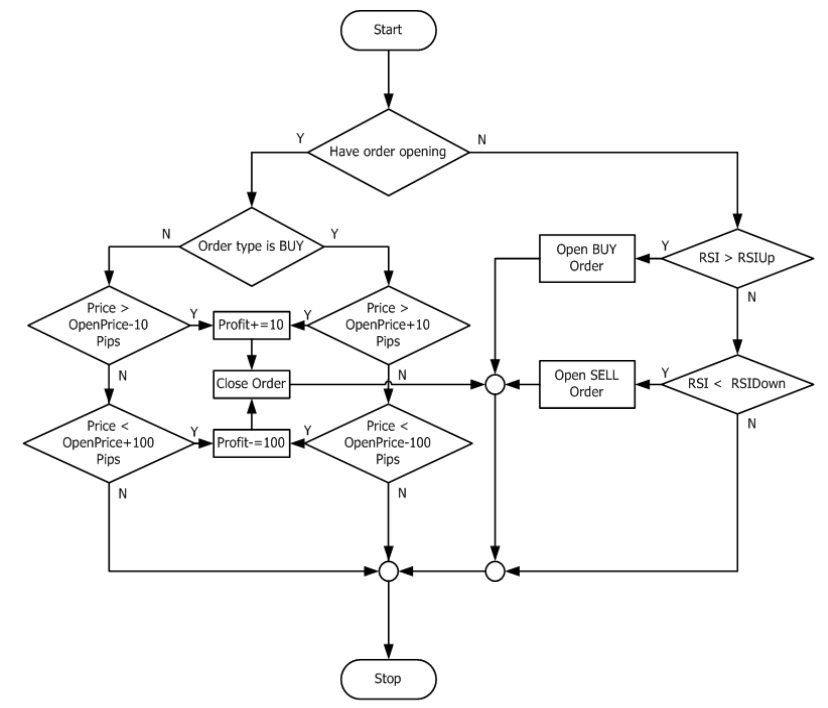

Fig. 1. Flow chart of an automatic trading system.

Upon testing, we limit RSI Up ranging in between 60-90 and RSI Down ranging in 10-40 from the price data from May 3, 2010 to July 6, 2010 based on EURO-US\$ currency exchange rates. The procedure of the test is as follows: First, we use exchange rate for the first 20 days to find profit and loss by using every value of the RSI Up and RSI Down, and then repeat the same action by recalculating for every 5 days for 8 times. Finally we plot the results as shown in Fig. 2 A to H. 


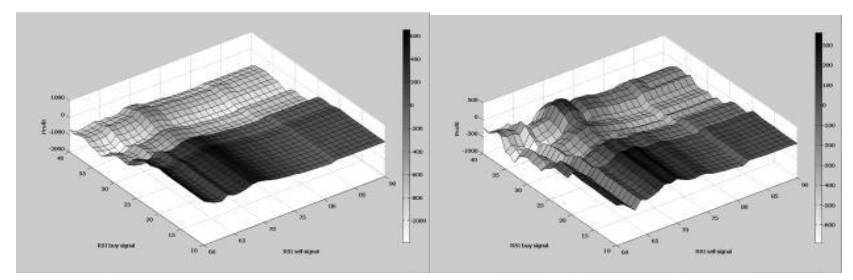

A.
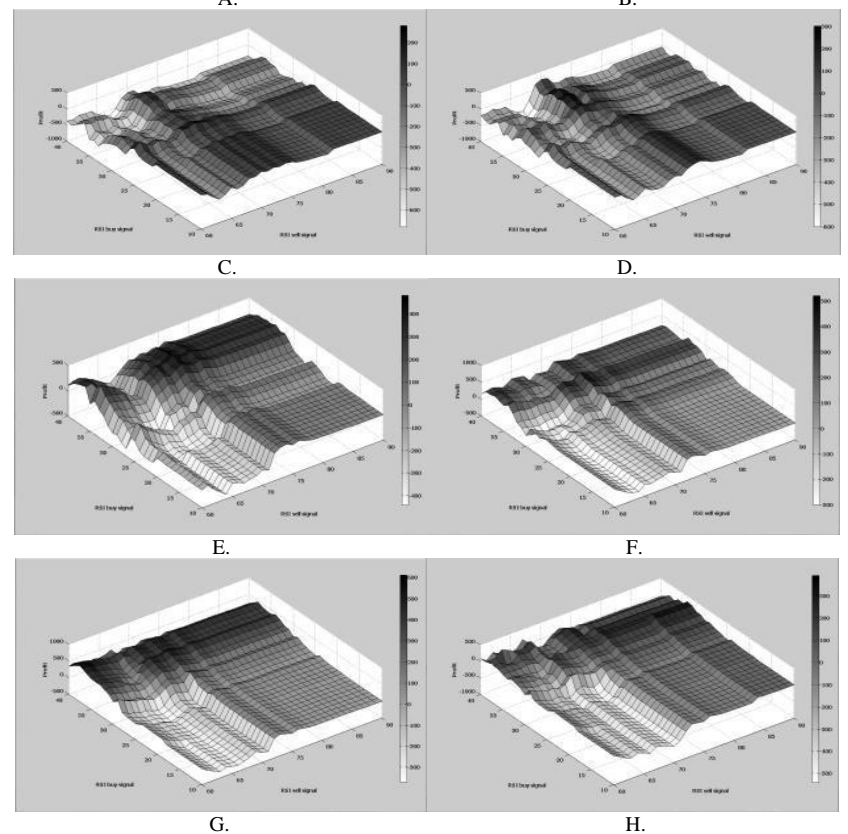

Fig. 2. Profit and loss for the first 20 days-period recalculating by shifting the data for every 5 days.

According to the experimental results, although we use the same parameters, profit / loss can turn around differently depending on time period in consideration. For example, Fig. 2-a, if we set RSI Down lower than 20, the results are positive at all values of RSI Up and the system will gets most profitable with RSI Up in 67-69 range. This means that the trend of exchange rate is bearish. In this case, the system should be an open-sell order strategy rather than a buy order one. However, if the system parameter is set as the same values shown in period of Fig. 2-e, the system will get more loss. This is because the exchange rate in this period is bullish The graph shows RSI Up and RSI Down which get most profits ranging in 30-40 and 70-90. The strategy should be open-buy order rather than sell- order. Moreover, if the system is set RSI Up ranging in 67-69 and is set RSI Down to 20 , it can get the most profit as shown in Fig. 2-a. Nevertheless, the same period yields the great loss in Fig. 2-e.

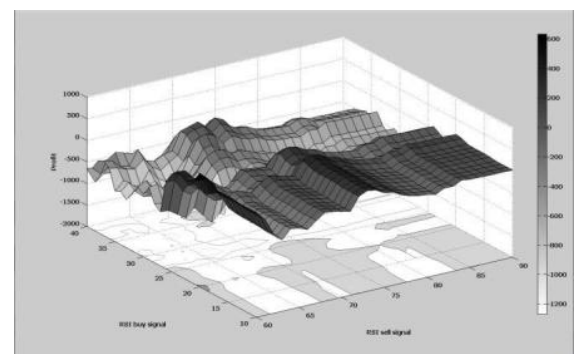

Fig. 3. Profit - loss of all RSI values throughout the experiment.

Fig. 3 depicts profit and loss when we extend period to all data starting from May 3, 2010 to July 6, 2010. The result is a system with the most profit at RSI Up and RSI Down about 61 and 20, which will use these constants for comparison the system (to be fixed RSI). Fig. 4 shows components of the adaptive RSI automatic trading system for which the parameter forecasting service using fuzzy time series to forecast the next values of RSI Up and RSI Down and sending new parameters to the automatic trading application. The new parameter is fed to update decision control of the automatic trading system. This research uses Meta Trader 4 Platform [8], which has a function called the Expert Advisor in supporting the automatic trading system. The advantage of this system is that the two subsystems work separately between the forecasting service and the trading system. In doing so, if some error occurs, the subsystem will not be detrimental to the overall system.

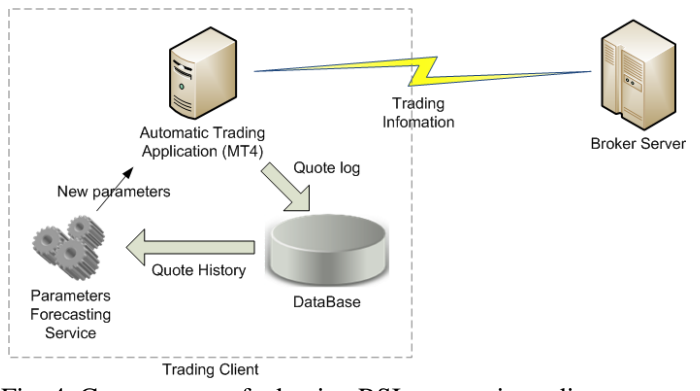

\section{Forecast Parameters With FuZZy Time SERIES}

In the previous section, if the system has been adjusted the parameters to the optimal ones, performance of the system should be significantly enhanced. Adopting this concept, this paper uses fuzzy time-series [9], [10] to forecast the trend of parameter changes (RSI Up, RSI Down) to gain the profit. We hypothesize that expectation of RSI Up and RSI Down of the series at two sets are related, and are parameters of the system. This paper proposes a prediction using two sets of time series with correlation. The concept is modified from Chen's Method [5] using vector concept to solve the problem. The procedures are as follows:

\section{A. Define Scope Universe Of Discourse U on 2 Sets of Time Series, Divided Them to J and $K$ into Equal Parts.}

The boundary of RSI Up is 60-90 and the boundary of RSI Down is $10-40$. Hence, the member of $U_{j}$ is ranging in between $60-90$ splitting $\mathrm{j}$ into 10 equal part. Similarly, the member of $U_{k}$ is between from 60 to 90 and splits k into 10 equal parts.

B. Define Membership Function of $U_{j}$ and $U_{k}$ after that,

Fuzzify Historical Data by the Membership Functions.

Since $\mathrm{j}$ and $\mathrm{k}$ is divided into 10 equal parts, the fuzzy membership function can be defined as shown in Fig. 5 .
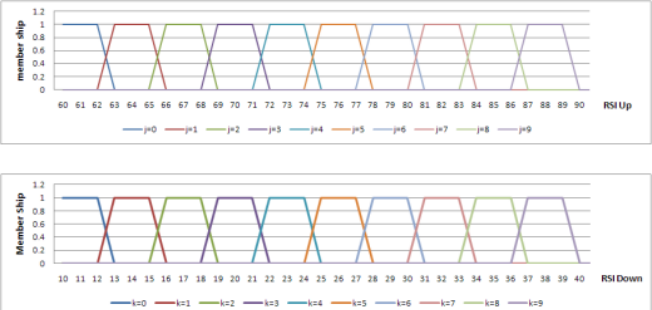

Fig. 5. Membership functions of $U_{j}$ and $U_{k}$ 
Utilizing historical data to find the RSI Up and RSI Down in the most profitable exchange rate using a 3-day period and then shift the data to recalculate by employing the same test method for all data. RSI Down has the same multiple maximum profits. We select a value that is the shortest distance from the last state and then fuzzify data by membership function. The result is shown in Table I.

TABLE I: RSI UP, RSI DOWN OF THE MOST PROFIT AND FUZZIFIED RESULTS.
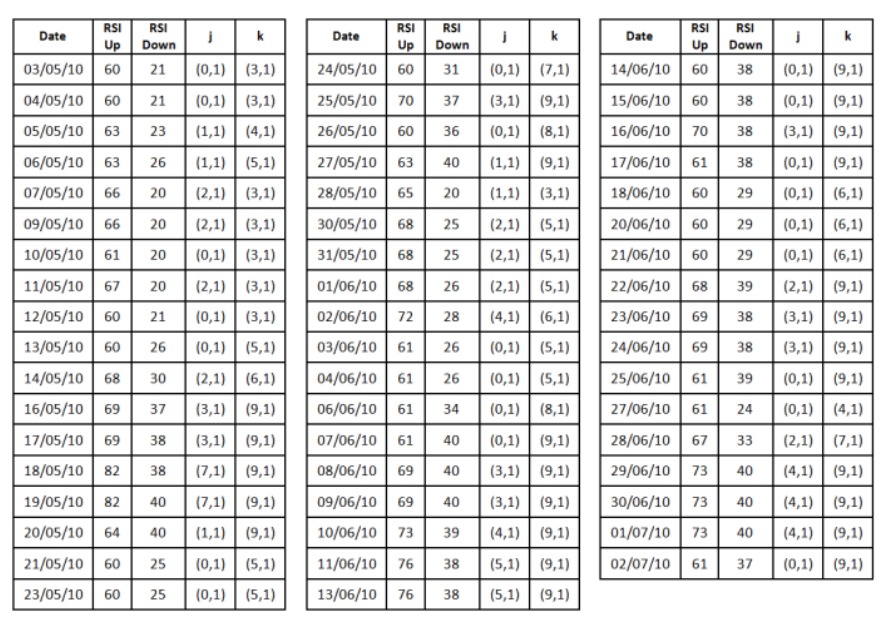

\section{Find Fuzzy Relationship From State Relation Using Fuzzified Results.}

This time series contain 2 sets of relations. The fuzzy relations $A_{j}$ are extended to define each value of $\mathrm{j}$ and $\mathrm{k}$. Therefore the fuzzy relations can be defined as $A_{j, k}$. Determination of the relationship can be done by finding a state with $\mathrm{j}$ and $\mathrm{k}$ corresponding to $\mathrm{j}, \mathrm{k}$ of $A_{j, k}$. According to relation table and are then updated value $\mathrm{j}$ and $\mathrm{k}$ of $A_{j, k}$. Repeat the same step until all $A_{j, k}$ are well defined. Next state relation table for time series of all $A_{j, k}$ is shown in Table II.

D. Calculate Forecast Output Table from Next State Relation Table Based on 3 Rules with Adapted From Chen's Method [4] as Follows.

1) If $(j, k)$ has only one member of fuzzy relationship which is $\left(j_{p}, k_{q}\right)$, then the midpoints of $j_{p}$ is $m_{j_{p}}$ and midpoints of $k_{q}$ is $m_{k_{q}}$ respectively. Forecasted output of $(j, k)$ is $\left(m_{j_{p}}, m_{k_{q}}\right)$.

2) If $(j, k)$ members of relationship are $\left\{\left(j_{1}, k_{1}\right)\right.$, $\left.\left(j_{2}, k_{2}\right),\left(j_{3}, k_{3}\right), . .,\left(j_{p}, k_{q}\right)\right\}$ and then number of members is $\mathrm{n}$. Midpoints of $j_{1}, j_{2}, j_{3}, \ldots, j_{p}$ are $m_{j_{1}}, m_{j_{2}}, m_{j_{3}}, . ., m_{j_{p}}$ and midpoints of $k_{1}, k_{2}, k_{3}, . ., k_{p}$ are $m_{k_{1}}, m_{k_{2}}, m_{k_{3}}, . ., m_{k_{q}}$ respectively. Forecasted output of $(j, k)$ is

$\left(\frac{\left[m_{j_{1}}+m_{j_{2}}+m_{j_{3}}+\ldots+m_{j_{p}}\right]}{n}, \frac{\left[m_{k_{1}}+m_{k_{2}}+m_{k_{3}}+\ldots+m_{k_{q}}\right]}{n}\right)$.

3) If $(j, k)$ is not a member of fuzzy relationship, then the midpoint of $\mathrm{j}$ is $m_{j}$ and the midpoint of $\mathrm{k}$ is $m_{k}$ Forecasted output of $(j, k)$ is $\left(m_{j}, m_{k}\right)$.

Table 1 , the values $\mathrm{j}$ and $\mathrm{k}$ of the next state are filled in the

TABLE II: NEXT STATE RELATION TABLE.

\begin{tabular}{|c|c|c|c|c|c|c|c|c|c|c|c|}
\hline Index & $\kappa$ & 0 & 1 & 2 & 3 & 4 & 5 & 6 & 7 & 8 & 9 \\
\hline$J$ & Range & $10-12$ & $13-15$ & $16-18$ & $19-21$ & $22-24$ & $25-27$ & $28-30$ & $31-33$ & $34-36$ & $37-39$ \\
\hline 0 & $60-62$ & & & & $\begin{array}{l}(2,1),(3,1) ;(0,1),(3,1) \\
(1,1),(4,1) ;(0,1),(5,1)\end{array}$ & $(2,1),(7,1) ;$ & $\begin{array}{l}(0,1),(5,1) ;(0,1),(5,1) ; \\
(2,1),(6,1) ;(0,1),(7,1) ; \\
(0,1),(8,1) ;\end{array}$ & $\begin{array}{l}(0,1),(6,1) ;(0,1),(6,1) ; \\
(2,1),(9,1) ;\end{array}$ & $(3,1),(9,1) ;$ & $\begin{array}{l}(0,1),(9,1) ; \\
(1,1),(9,1)\end{array}$ & $\begin{array}{l}(0,1),(4,1) ;(0,1),(6,1) ; \\
(0,1),(9,1) ;(3,1),(9,1) ; \\
(3,1),(9,1) ;\end{array}$ \\
\hline 1 & $63-65$ & & & & $(2,1),(5,1)$ & $(1,1),(5,1) ;$ & $(2,1),(3,1)$ & & & & $\begin{array}{l}(1,1),(3,1) \\
(0,1),(5,1) ;\end{array}$ \\
\hline 2 & $66-68$ & & & & $\begin{array}{l}(0,1),(3,1) ;(0,1),(3,1) ; \\
(2,1),(3,1) ;\end{array}$ & & $\begin{array}{l}(2,1),(5,1) ;(2,1),(5,1) ; \\
(4,1),(6,1) ;\end{array}$ & $(3,1),(9,1) ;$ & $(4,1),(9,1) ;$ & & $(3,1),(9,1) ;$ \\
\hline 3 & $69-71$ & & & & & & & & & & $\begin{array}{l}(0,1),(8,1) ;(0,1),(9,1) ; \\
(0,1),(9,1) ;(3,1),(9,1) ; \\
(3,1),(9,1) ;(3,1),(9,1) ; \\
(4,1),(9,1) ;(7,1),(9,1) ;\end{array}$ \\
\hline 4 & $72-74$ & & & & & & & $(0,1),(5,1) ;$ & & & $\begin{array}{l}(0,1),(9,1) ;(4,1),(9,1) ; \\
(4,1),(9,1) ;(5,1),(9,1) ;\end{array}$ \\
\hline 5 & $75-77$ & & & & & & & & & & $\begin{array}{l}(0,1),(9,1) ; \\
(5,1),(9,1) ;\end{array}$ \\
\hline 6 & $78-80$ & & & & & & & & & & \\
\hline 7 & $81-83$ & & & & & & & & & & $\begin{array}{l}(1,1),(9,1) ; \\
(7,1),(9,1) ;\end{array}$ \\
\hline 8 & $84-85$ & & & & & & & & & & \\
\hline 9 & $87-89$ & & & & & & & & & & \\
\hline
\end{tabular}

Using these procedures summarized in Table II, the forecasted results can be written in Table III. To predict RSI Up, RSI Down in the next period, we examine the RSI Up, RSI Down by matching to the Profit Max in the current period $\mathrm{j}, \mathrm{k}$ corresponding to the same range. We then take the output at the position value of $\mathrm{j}$, and $\mathrm{k}$ as the expectation values. 
TABLE III: FORECASTED OUTPUT TABLE.

\begin{tabular}{|c|c|c|c|c|c|c|c|c|c|c|c|}
\hline Index & $K$ & 0 & 1 & 2 & 3 & 4 & 5 & 6 & 7 & 8 & 9 \\
\hline$J$ & Range & $10-12$ & 13-15 & $16-18$ & $19-21$ & $22-24$ & $25-27$ & $28-30$ & $31-33$ & $34-36$ & $37-39$ \\
\hline 0 & $60-62$ & \begin{tabular}{|l|}
61, \\
11
\end{tabular} & $\begin{array}{l}61, \\
14\end{array}$ & $\begin{array}{l}61, \\
17\end{array}$ & $\begin{array}{l}63.25 \\
22.25\end{array}$ & $\begin{array}{l}67, \\
32\end{array}$ & $\begin{array}{l}62.2, \\
29.6\end{array}$ & $\begin{array}{l}63, \\
32\end{array}$ & $\begin{array}{l}70, \\
38\end{array}$ & $\begin{array}{l}62.5, \\
38\end{array}$ & $\begin{array}{l}64.6, \\
33.2\end{array}$ \\
\hline 1 & $63-65$ & \begin{tabular}{|l}
64, \\
11
\end{tabular} & $\begin{array}{l}64, \\
14\end{array}$ & $\begin{array}{l}64, \\
17\end{array}$ & $\begin{array}{l}67, \\
26\end{array}$ & $\begin{array}{l}64, \\
26\end{array}$ & $\begin{array}{l}67, \\
20\end{array}$ & $\begin{array}{l}64, \\
29\end{array}$ & $\begin{array}{l}64, \\
32\end{array}$ & $\begin{array}{l}64, \\
35\end{array}$ & $\begin{array}{l}62.5 \\
23\end{array}$ \\
\hline 2 & $66-68$ & \begin{tabular}{|l|}
67, \\
11
\end{tabular} & \begin{tabular}{|l}
67, \\
14
\end{tabular} & \begin{tabular}{|l}
67, \\
17
\end{tabular} & \begin{tabular}{|l|}
63, \\
20
\end{tabular} & \begin{tabular}{|l|}
63, \\
23
\end{tabular} & $\begin{array}{l}69, \\
27\end{array}$ & $\begin{array}{l}70 \\
38\end{array}$ & \begin{tabular}{|l}
73 \\
38
\end{tabular} & \begin{tabular}{|l|}
63, \\
35
\end{tabular} & $\begin{array}{l}70 \\
38\end{array}$ \\
\hline 3 & $69-71$ & \begin{tabular}{|l}
70, \\
11
\end{tabular} & $\begin{array}{l}70, \\
14\end{array}$ & $\begin{array}{l}70 \\
17\end{array}$ & \begin{tabular}{|l}
70 \\
20
\end{tabular} & $\begin{array}{l}70 \\
23\end{array}$ & $\begin{array}{l}70, \\
26\end{array}$ & $\begin{array}{l}70, \\
29\end{array}$ & $\begin{array}{l}70, \\
32\end{array}$ & \begin{tabular}{|l}
70, \\
35
\end{tabular} & \begin{tabular}{|l}
68.5 \\
37.625
\end{tabular} \\
\hline 4 & $72-74$ & \begin{tabular}{|l|}
73 \\
11
\end{tabular} & \begin{tabular}{|l}
73, \\
14
\end{tabular} & $\begin{array}{l}73, \\
17\end{array}$ & $\begin{array}{l}73, \\
20\end{array}$ & $\begin{array}{l}73, \\
23\end{array}$ & $\begin{array}{l}73, \\
26\end{array}$ & \begin{tabular}{|l}
61, \\
26
\end{tabular} & $\begin{array}{l}73, \\
32\end{array}$ & $\begin{array}{l}73, \\
35\end{array}$ & $\begin{array}{l}70.75 \\
38\end{array}$ \\
\hline 5 & $75-77$ & \begin{tabular}{|l}
76, \\
11
\end{tabular} & $\begin{array}{l}76, \\
14\end{array}$ & $\begin{array}{l}76, \\
17\end{array}$ & $\begin{array}{l}76, \\
20\end{array}$ & $\begin{array}{l}76, \\
23\end{array}$ & $\begin{array}{l}76, \\
26\end{array}$ & $\begin{array}{l}76, \\
29\end{array}$ & $\begin{array}{l}76, \\
32\end{array}$ & $\begin{array}{l}76, \\
35\end{array}$ & $\begin{array}{l}68.5 \\
38\end{array}$ \\
\hline 6 & $78-80$ & $\begin{array}{l}79, \\
11\end{array}$ & \begin{tabular}{|l}
79, \\
14
\end{tabular} & $\begin{array}{l}79, \\
17\end{array}$ & $\begin{array}{l}79, \\
20\end{array}$ & $\begin{array}{l}79, \\
23\end{array}$ & $\begin{array}{l}79, \\
26\end{array}$ & $\begin{array}{l}79 \\
29\end{array}$ & $\begin{array}{l}79, \\
32\end{array}$ & $\begin{array}{l}79, \\
35\end{array}$ & $\begin{array}{l}79, \\
38\end{array}$ \\
\hline 7 & $81-83$ & \begin{tabular}{|l}
82, \\
11
\end{tabular} & $\begin{array}{l}82, \\
14\end{array}$ & $\begin{array}{l}82, \\
17\end{array}$ & $\begin{array}{l}82, \\
20\end{array}$ & $\begin{array}{l}82, \\
23\end{array}$ & $\begin{array}{l}82, \\
26\end{array}$ & $\begin{array}{l}82, \\
29\end{array}$ & $\begin{array}{l}82, \\
32\end{array}$ & $\begin{array}{l}82, \\
35\end{array}$ & $\begin{array}{l}73 \\
38\end{array}$ \\
\hline 8 & $84-85$ & $\begin{array}{l}85, \\
11\end{array}$ & $\begin{array}{l}85, \\
14\end{array}$ & $\begin{array}{l}85, \\
17\end{array}$ & $\begin{array}{l}85, \\
20\end{array}$ & $\begin{array}{l}85, \\
23\end{array}$ & $\begin{array}{l}85, \\
26\end{array}$ & $\begin{array}{l}85, \\
29\end{array}$ & $\begin{array}{l}85, \\
32\end{array}$ & $\begin{array}{l}85 \\
35\end{array}$ & $\begin{array}{l}85 \\
38\end{array}$ \\
\hline 9 & $87-89$ & \begin{tabular}{|l|}
88, \\
11
\end{tabular} & $\begin{array}{l}88, \\
14\end{array}$ & $\begin{array}{l}88, \\
17\end{array}$ & $\begin{array}{l}88, \\
20\end{array}$ & $\begin{array}{l}88, \\
23\end{array}$ & $\begin{array}{l}88, \\
26\end{array}$ & \begin{tabular}{|l}
88, \\
29
\end{tabular} & $\begin{array}{l}88, \\
32\end{array}$ & $\begin{array}{l}88, \\
35\end{array}$ & \begin{tabular}{|l}
88, \\
38
\end{tabular} \\
\hline
\end{tabular}

\section{EXPERIMENTAL RESULTS}

The experiment is designed to aim for two parts: First part is experiment for estimation of appropriate RSI Up and RSI Down for the next steps. This result will be compared to actual time series that enables to determine the prediction ability. Second part is the experiment on adjusting RSI Up and RSI Down for the automatic trading system. The result of second part will be compared to the automatic trading system with fixed parameters at most profit for all periods. In the experiment, we use the exchange rate of Euro US\$ (EURUSD) in the period from May 3, 2010 to July 6, 2010.

Fig. 6 shows the results obtained from the first part when the actual data and predicted data are plotted in comparison.
As we have seen, the predictions of RSI Up and RSI Down are agreed as in the same direction with the actual data. But there are still some errors. We will measure errors by using root mean squared errors shown in equation (1).

$R M S E=\sqrt{\frac{\sum_{i=1}^{n}\left(\text { ActualRSI }_{i}-\text { ForecastRSI }_{i}\right)^{2}}{n}}$

From the measured values, the RMSE of RSI Up is located at 4.583 and RMSE of RSI Down at 2.788 errors may be reduced if we extend the time series or adding more data.

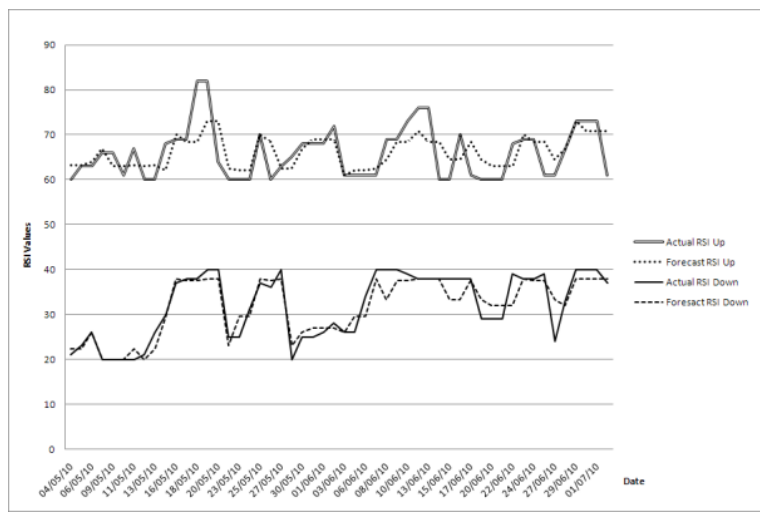

Fig. 6. Forecast outputs compared to actual values.

Fig. 7 shows the results from the second part using the RSI Up and RSI Down prediction to control the opening order of the system. The results are compared with those of fixed RSI at the maximum profit. As can be seen, the graph of adaptive RSI has continuously increased earning profits, while that of the fixed RSI yields increased earning profit at first and then turns around to be a decrease one as time goes by. This is because the market trend has been changed.

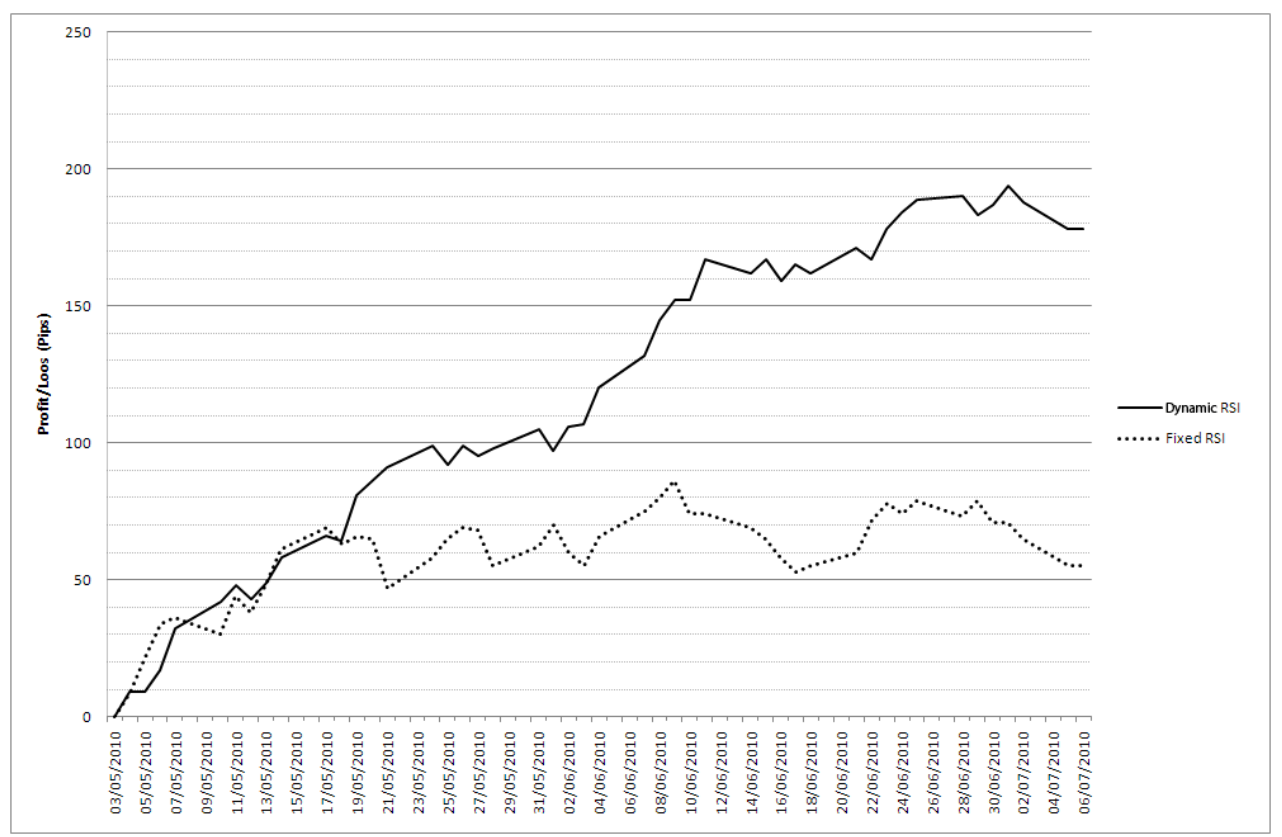

Fig. 7. Comparison on the growth profit between fixed RSI and dynamic RSI using fuzzy time series.

\section{V.CONCLUSIONS}

Following the proposed investment algorithm using fuzzy time series, the results show that the adjustment parameters of the proposed automatic trading system can actually increase the profits of the system. Even though there is small error in the forecast accuracy of some parameters, but the results are better than those using the fixed parameters. 
Because the slope of the curve of the profit to parameter is not high, the small error of the estimation has not much affected to the performance. As a result, it is only little diminished a profit, but it does not cause the loss eventually.

This study considers only the conditions of order opening, which is only one factor in causing the profits. Nevertheless, in some extension, a more practical automatic trading system has other factors. For example, conditions of order closing and order management are those influent factors to be considered. In spite of existence of a more complicated system, a simple one is shown in this paper to initiate and first validate the effectiveness of the proposed method. The more complex system as mentioned will be suited for future work.

\section{REFERENCES}

[1] K. Chi, F. P. Fu, and W. G. Che, "A modified model of fuzzy time series for forecasting exchange rates," International Workshop on Education Technology and Computer Science, vol. 3, no. 2, pp. 40-43, 2010.

[2] Y. Leu, C. P. Lee, and Y. Z. Jou, "A distance-based fuzzy time series model for exchange rates forecasting," Expert Systems with Applications, vol.36, pp 8107-8114, 2009.

[3] T. Stridsman, Trading systems that work: building and evaluating effective trading systems, New York: McGraw-Hill, 2000, pp 3-115.

[4] P. J. Kaufman, New trading systems and methods, $3^{\text {rd }}$ ed, New Jersey: John Wiley andSons, 2005, pp 153-200.

[5] S. M. Chen, "Forecasting enrollments based on fuzzy time series," Fuzzy Sets and Systems, vol. 81, no.3, pp.311-319, 1996.
[6] J. Murphy, Technical analysis of the financial markets, New York: Prentice Hall, 1986, pp. 255-262.

[7] E. Ponsi, FOREX Patterns and Probabilities: trading strategies for trending and range-bound markets, New Jersey: John Wiley andSons, 2007, pp 51-91.

[8] Meta Quotes Software. (2000). MQL4 Reference. [Online]. Available: http://docs.mq14.com/index.html

[9] Q. Song and B.S. Chissom, "Forecasting enrollments with fuzzy time series Part I," Fuzzy Sets and Systems, vol. 54, no.1, pp.1-9, 1993.

[10] Q. Song and B.S. Chissom, "Forecasting enrollments with fuzzy time series Part II," Fuzzy Sets and Systems, vol. 62, no.1, pp.1-8, 1994.

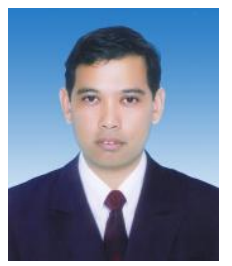

Kraimon Maneesilp was born in Thailand. He received a B.Ind and M.Eng from King Mongkut's Institute of Technology Ladkrabang. His research interests include Financial Information Behavior, nonlinear forecasting and Automatic Trading System. $\mathrm{He}$ is working toward his Doctoral degree at the school of Computer Engineering Faculty of Engineering, King Mongkut's Institute of Technology Ladkrabang, Ladkrabang, Bangkok, Thailand.

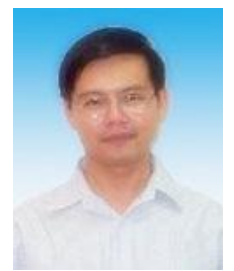

Pitikhate Sooraksa was born in Thailand. He is currently Associate Professor of Electrical Engineering at the School of Computer Engineering and Information Science, Faculty of Engineering, King Mongkut's Institute of Technology Ladkrabang, Ladkrabang, Bangkok, Thailand. His research interests include IT nonlinear systems and computer-aided control. He received a B.Ed. (Hons) and M.Sc. in Physics from Srinakharinwirot Univer- sity, an M.S. from George Washington University(1992) and a. Ph.D. from the University of Houston(1996), both in Electrical Engineering. 